HÖPEL, Thomas, Emigranten der Französischen Revolution in Preußen (1789-1806). Eine Studie in vergleichender Perspektive

\title{
Karine Rance
}

\section{OpenEdition}

Édition électronique

URL : http://journals.openedition.org/ifha/1195

DOI : $10.4000 /$ ifha. 1195

ISSN : 2198-8943

\section{Éditeur}

IFRA - Institut franco-allemand (sciences historiques et sociales)

\section{Référence électronique}

Karine Rance, «HÖPEL, Thomas, Emigranten der Französischen Revolution in Preußen (1789-1806). Eine Studie in vergleichender Perspektive », Revue de l'IFHA [En ligne], Date de recension, mis en ligne le 01 janvier 2002, consulté le 22 septembre 2020. URL : http://journals.openedition.org/ifha/1195 ; DOI : https://doi.org/10.4000/ifha. 1195

Ce document a été généré automatiquement le 22 septembre 2020.

(CIFHA 


\title{
HÖPEL, Thomas, Emigranten der Französischen Revolution in Preußen (1789-1806). Eine Studie in vergleichender Perspektive
}

\author{
Karine Rance
}

1 T.H. présente ici la version remaniée de sa thèse préparée sous la double tutelle de M. Middell et de H. Siegrist à l'université de Leipzig. L'étude porte sur les émigrés français et sur les populations issues des régions rhénanes, des Provinces-Unies et des Pays-Bas autrichiens envahis par la France révolutionnaire. L'objectif est d'analyser les logiques à l'œuvre dans l'accueil qui leur est offert par la Prusse. Le sous-titre de l'ouvrage évoque une perspective comparative qui est effectivement menée avec la Saxe électorale.

Dans le contexte de la sécularisation et de la formation de l'État-nation, T.H. s'interroge sur l'effet de l'émigration sur la politique menée en Prusse et en Saxe à l'égard des étrangers. L'étude de la pratique administrative par l'analyse du discours des fonctionnaires en charge de la question des émigrés est au cœur de ce travail. Dans la première partie, T.H. considère le cadre législatif et son application dans les différentes régions. Il oriente ensuite son enquête vers l'image des émigrés dans l'administration, la noblesse et la population. La troisième partie porte sur les transferts culturels dont la faiblesse s'explique en partie par la forte représentation des nobles parmi les émigrés présents dans les régions étudiées ( $42 \%$ contre $20 \%$ de membres du tiers état). Cette analyse des transferts donne lieu à une étude comparée du degré d'ouverture et de modernité des économies prussienne et saxonne.

La crainte d'une diffusion des idées " françaises ", terme synonyme de " révolutionnaires ", et les exigences de la politique internationale rendent compte de la sévérité des mesures prises à l'encontre des étrangers. En Prusse comme en Saxe (qui calque sa politique sur celle de sa voisine), les premières mesures sont prises après la défaite de 1792 pour empêcher les émigrés d'arriver en masse. Elles sont ensuite 
renforcées graduellement jusqu'au départ des acteurs de l'émigration (vers 1800-1804). La même politique est menée à l'égard de tous les étrangers, mais les émigrés français sont clairement distingués des autres par l'administration prussienne. T.H. relève ainsi l'émergence d'une nouvelle catégorie, celle de l'émigré politique, considéré, au même titre que le vagabond, comme un danger potentiel pour l'ordre public. Même naturalisé, l'étranger n'obtient pas les mêmes droits que les sujets nés dans le royaume : les hauts postes de l'administration ou de l'armée lui restent fermés. Le ius sanguinis de 1842 doit donc être replacé dans cette perspective. "La pratique étatique apparaît comme un moteur d'intégration culturelle qui s'exprime non seulement par la stabilisation des représentations de soi et de l'autre, mais surtout par l'introduction progressive du paradigme Staatsbürger/ Ausländer » écrit T.H. (p. 381). Une analyse particulièrement intéressante par la précision de l'enquête menée sur l'émigration, mais aussi par l'étude des réactions et des adaptations de l'appareil administratif. 